\title{
Molecular Diagnosis of Chronic Respiratory Disease Associated with Mycoplasma gallisepticum in Ducks
}

\author{
N. Aiswarya ${ }^{1}$, Surya Sankar ${ }^{1}$, Roshin M. Reji ${ }^{1}$, P. S. Reshma ${ }^{1}$, \\ S. Reshma ${ }^{1}$, A. Aneesh ${ }^{1}$, K. Krithiga ${ }^{2}$ and M. Mini ${ }^{1}$ \\ ${ }^{1}$ Department of Veterinary Microbiology, ${ }^{2}$ Department of Veterinary Pathology, College of \\ Veterinary and Animal Sciences, Mannuthy, Thrissur, India \\ *Corresponding author
}

\section{A B S T R A C T}

Keywords

Chronic respiratory disease (CRD),

Mycoplasma gallisepticum, Ducks, Polymerase Chain Reaction (PCR)

Article Info

Accepted:

17 October 2020

Available Online:

10 November 2020
Three birds aged six weeks belonging to a private farm in Thrissur district were brought to the department of Veterinary Microbiology, college of Veterinary and Animal sciences, Mannuthy for disease investigation. The owner reported that a total of about 50animals in the team experienced severe respiratory distress. The clinical signs observed in the ducks characterized by coryza, conjunctivitis, respiratory rales and sneezing. The post mortem lesions in lungs were suggestive of chronic respiratory disease (CRD). On culturing the clinical samples, no bacteria could be isolated. Lung tissue was processed and subjected to polymerase chain reaction (PCR) targeting Mycoplasma gallisepticum species. Samples revealed amplicon size of $183 \mathrm{bp}$.

\section{Introduction}

Chronic respiratory disease is considered as one of the most economically significant diseases of poultry, caused by several pathogens. Among them, M.gallisepticum is the most important pathogen causing CRD in chickens (Ley and Yoder, 1997) and infectious sinusitis in turkey. Chronic Respiratory Disease affects mainly chicken, but turkey, pheasants, geese, pigeons, psittacine birds and rarely ducks are also getting infected. The disease is characterized by coryza, conjunctivitis, respiratory rales and sneezing in chicken. The present study describes the molecular detection of M.gallisepticum among ducks from a private farm in Thrissur district. The owner reported that the birds have been treated with antibiotics like Co-trimoxazole, Amoxycillinclavulanic acid and Enrofloxacin and were not responding to the therapy. The birds were submitted to the department of Veterinary Pathology, COVAS, Mannuthy for 
postmortem examination. The samples were collected aseptically and send to the department of Veterinary Microbiology for detailed investigation.

\section{Materials and Methods}

On postmortem, lesions in lungs were suggestive of CRD. The samples were inoculated on to Blood agar (BA) and Sabouraud's dextrose agar (SDA). Blood agar plates were incubated at $37^{\circ} \mathrm{C}$ for $24-48 \mathrm{~h}$ and duplicate samples on SDA plates were incubated at $37^{\circ} \mathrm{C}$ and at room temperature. Since no specific medium for Mycoplasma was readily available, we proceed for the molecular detection.

For conducting M.gallisepticum species specific Polymerase Chain Reaction (PCR), lung tissues were transferred to a sterile mortar and pestle and $5 \mathrm{~mL}$ of $0.8 \%$ phosphate buffered saline was added. Tissues were triturated and pelleted by centrifugation at
$8000 \mathrm{rpm}$ for $10 \mathrm{~min}$. The supernatant was discarded and pellet was subjected to further lysis and DNA extraction using HiPurA multi sample DNA purification kit. Polymerase chain reaction was conducted using M. gallisepticum species specific PCR as per OIE, 2008. Template DNA from M.gallisepticum vaccine (NobilisIntervet, India) was kept as positive control.

\section{Results and Discussion}

In the present study, no bacterial organisms of pathogenic significance could be isolated on BA even after incubation up to $72 \mathrm{~h}$. No growth could be observed on SDA even after incubation at room temperature for 7 days. It may be attributed to the antibiotic therapy already started for the flock. The PCR was found to be positive for M.gallisepticum which revealed an amplicon size of $183 \mathrm{bp}$ in electrophoresed gel under UV transillumination (Fig. 1).

Fig.1 Polymerase chain reaction assay depicting the detection of M. gallisepticum from ducks

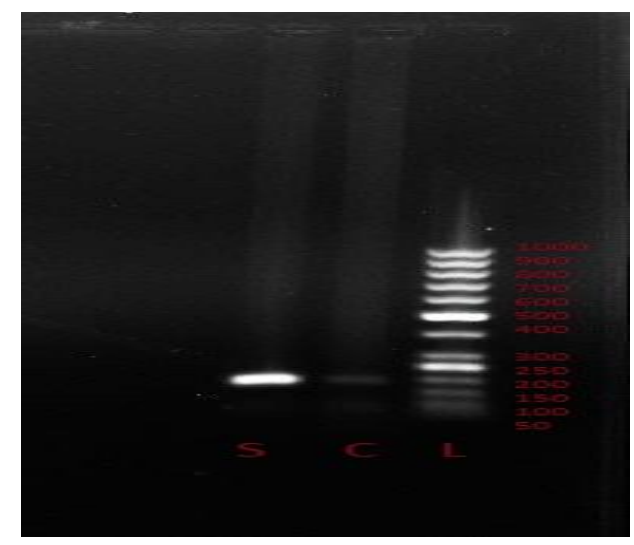

Diagnosis of avian mycoplasmosis can be done by various methods, but the gold standard test for confirmation of diagnosis is isolation and identification of the organism (Ley, 2008).It takes at least two weeks for cultural isolation, and the procedure is laborious too. Molecular techniques such as
PCR are found to be highly sensitive and specific for the detection of Mycoplasma (Abdelwhab et al., 2011). Polymerase chain reaction assays offer a rapid and a sensitive method for the detection and identification of M.gallisepticum directly from the clinical samples (Nascimento et al., 1991; Callison et 
al., 2006, Hess et al., 2007, Sankar et al., 2012). According to Evans and Leigh (2008), PCR technique alone can be used for the confirmative diagnosis of M.gallisepticum. In the present study, positive results were obtained within $24 \mathrm{~h}$ with PCR, which enables an accurate and timely diagnosis.

The present study deals with the molecular detection of M.gallisepticum infection in ducks using polymerase chain reaction.

\section{References}

Abdelwhab, E. M., Abdelmagid, M. A. ElSheibeny, L. M., El-Nagar, H. A., Arafa, A., Selim, A., Nasef, S. A., Aly, M. M. and Hafez, H. M. 2011. Detection and molecular characterization of Mycoplasma gallisepticum field infection in TS-11-vaccinated broiler breeders. 20 (3):390-396.

Callison, S. A., Riblet, S. M., Sun, S., Ikuta, N., Hilt, D., Leiting, V., Kleven, S. H., Suarez, D. L. and Garcia, M. 2006. Development and validation of a realtime Taqman polymerase chain reaction assay for the detection of Mycoplasma gallisepticum in naturally infected birds.Avian Dis. 50 (4): 537-544.

Evans, J. D. and Leigh, S. A. 2008. Differentiation of Mycoplasma gallisepticum vaccine strains ts-11 and 6/85 from commonly used Mycoplasma gallisepticum challenge strains by PCR. AvianDis. 52: 491-497.
Hess, M., Neubauer, C. and Hackl, R. 2007. Interlaboratory comparison of ability to detect nucleic acid of Mycoplasma gallisepticum and Mycoplasma synoviae by polymerase chain reaction. Avian Pathol. 36:127-133.

Ley, D. H., and H. W. Yoder, Jr., Mycoplasma gallisepticum infection. Pages 194-207 in: Diseases of Poultry. $9^{\text {th }}$ ed. B.W. Calnek, H. J. Barnes, C. W. Beard, L. R. McDougald, and Y. M. Saif, ed. Jr. 1997. Iowa State University Press, IA.

Nascimento, E. R., Yamamoto, R., Herrick, K. R. andTait, R. C. 1991. Polymerase chain reaction for detection of Mycoplasma gallisepticum. Avian Dis. 35: 62-69.

OIE Terrestrial Manual. 2008. Avian mycoplasmosis (Mycoplasma gallisepticum, Mycoplasma synoviae) In: Manual of Diagnostic Tests and Vaccines for Terrestrial Animals. Pp525-541.

Saif, Y. M., Fadley, A. M. and Glisson, J. R. 2008. Mycoplasma gallisepticum infection. in: Diseases of Poultry $12^{\text {th }} \mathrm{ed}$. L. R. McDougald, L. K. Nolan, and D. E. Swanye, Iowa State University Press, Ames, Iowa, Pages 807-834.

Sankar, S., G. K. Nair, M. Mini and H. M. Harshan. 2012. Polymerase chain reaction based detection of Mycoplsma gallisepticum in chicken. J. Ind. Vet. Assoc. 10(1): 5-8.

\section{How to cite this article:}

Aiswarya, N., Surya Sankar, Roshin M. Reji, P. S. Reshma, S. Reshma, A. Aneesh, K. Krithiga and Mini, M. 2020. Molecular Diagnosis of Chronic Respiratory Disease Associated with Mycoplasma gallisepticum in Ducks. Int.J.Curr.Microbiol.App.Sci. 9(11): 2382-2384. doi: https://doi.org/10.20546/ijcmas.2020.911.285 